\title{
Oviposition of fertile eggs and postponement of subsequent egg laying in ring doves (Streptopelia risoria)
}

\author{
Theresa O. Allen* \\ Department of Psychology, Duke University, Durham, North Carolina 27706, U.S.A.
}

Summary. Within the 45 days after an oviposition, fewer female doves which had laid fertile eggs laid a subsequent clutch than did females which had laid infertile eggs. During incubation the fertile eggs were replaced by infertile ones; therefore, this difference was not a result of raising squabs.

\section{Introduction}

After pairing, male and female ring doves (Streptopelia risoria) proceed through the stages of courtship, nest building, incubation of a clutch of $2 \mathrm{eggs}$, and brooding of squabs. The interval between the laying of eggs and the weaning of squabs is about 35 days. If allowed to remain together after raising squabs, ring dove pairs produce their next clutch of eggs about 41 days after the previous oviposition (Cuthbert, 1945). However, in this laboratory where partners are usually separated at the end of a breeding cycle, a clutch of new eggs, although seldom present in the nests of pairs weaning squabs, is often present in the nests of pairs whose eggs had failed to hatch (unpublished observation). These two groups can be distinguished by the presence or absence of developing squabs. In addition, the eggs which did not hatch could have been either infertile or fertile.

The purpose of the present study was to separate the condition of the eggs at the time of oviposition from the presence of squabs at the end of the incubation period.

\section{Materials and Methods}

The ring doves (Streptopelia risoria) used were 28 males and 48 females which had completed at least two successful breeding cycles by raising squabs to weaning. All pairs were housed in the Duke University colony in wooden breeding cages $(81 \times 45 \times 36 \mathrm{~cm})$ equipped with food (Purina Coarse Chick Chow and oyster shell grit) and water dispensers, a glass nest bowl (10.8 $\mathrm{cm}$ ) and nest material (pine needles). All breeding rooms received $14 \mathrm{~h}$ light $/ 24 \mathrm{~h}$ and were maintained at $21-24^{\circ} \mathrm{C}$.

The doves were paired with unfamiliar partners, placed together in a breeding cage and allowed to lay eggs. Assignment to treatment groups (Table 1) was based on the fertility or infertility of this clutch. A fertile clutch was considered to be one in which at least one of the 2 eggs showed embryological development when held before a lamp: blood vessels are usually visible by this method after 3 days of incubation.

\section{Treatment groups}

Group $A$. For 10 pairs of doves fertile eggs were left in the nest for only a few hours $(0 \cdot 5-3 \cdot 5$ h). After removal, these eggs were given to surrogate parents for additional incubation before

* Present address: Department of Psychology, University of Pennsylvania, 3815 Walnut Street, Philadelphia, Pennsylvania 19104, U.S.A. 
candling, and infertile eggs were placed in the nest. The infertile eggs were produced by female/female pairs: the size and weight of these eggs do not differ significantly from those of eggs laid by females paired with males.

Group $B$. For 7 pairs of doves fertile eggs were left in the nest for the first 3-6 days of incubation. The eggs were then removed, candled, and replaced by infertile eggs recently laid by female/female pairs.

Group $C$. The infertile eggs laid by 11 pairs of doves were left in the nest for the first 3-6 days of incubation. These eggs were then removed, candled and replaced in the nest.

Group $D$. The 10 female/female pairs were allowed to lay 2 clutches of eggs. The first 2 eggs laid by the pair were left in the nest while the next 2 eggs were removed soon after laying. Females of a pair laid clutches within 1 day of each other (median; range $=0-3$ days).

In Groups A, B and C, male/female pairs were used. Experienced pairs, however, lay infertile eggs only infrequently, and this made it impractical to obtain an adequate number of infertile male/female pairs whose eggs would be removed within a few hours of laying. Infertile eggs are produced reliably when females are paired with other females (Whitman, 1919). The intervals between clutches of female/female pairs (collected as part of another study) are therefore included (Group D) for comparison with those of infertile male/female pairs.

All pairs were allowed à maximum of 45 days after oviposition to lay their subsequent clutch. Since the weight distribution and colour of infertile eggs change as they are incubated, stale eggs were replaced by fresh infertile ones. Periodic daily spot checks were performed to ensure that incubation was proceeding normally, and nests were inspected once daily to detect the subsequent clutch.

\section{Statistical analysis}

Latency to the subsequent clutch was defined as the interval between the laying of the first egg of the initial clutch and the laying of the first egg of the next clutch. Two-tailed Fisher Exact Probability and Mann-Whitney $U$ tests were used to analyse the number of laying pairs and the latency to the subsequent clutch, respectively (Siegal, 1956).

\section{Results}

The results are shown in Table 1.

\section{Number of laying pairs}

Oviposition of fertile eggs is associated with postponement of the subsequent clutch, even when the squab-care stage was precluded by introduction of infertile eggs soon after the

Table 1. Subsequent clutches of ring doves in male/female pairs (Groups A, B, C) laying fertile or infertile eggs and in female/female pairs (Group D)

\begin{tabular}{|c|c|c|c|c|c|c|}
\hline Group & $\begin{array}{c}\text { Type of eggs } \\
\text { (laid/incubated) }\end{array}$ & $\begin{array}{l}\text { Time of } \\
\text { removal }\end{array}$ & $\begin{array}{l}\text { No. of } \\
\text { pairs }\end{array}$ & $\begin{array}{l}\text { No. of laying } \\
\text { pairs } \\
(\%)\end{array}$ & $\begin{array}{l}\text { Latency (days) } \\
\text { to lay } \\
\text { (median and } \\
\text { range) }\end{array}$ & $\begin{array}{l}\text { Fertility of } \\
\text { subsequent } \\
\text { clutch (\%) }\end{array}$ \\
\hline A & Fertile/infertile & Immediate & 10 & $4(40) \dagger$ & $33 \cdot 5(32-35)$ & 100 \\
\hline B & Fertile/infertile & Delayed & 7 & $1(14)^{*}$ & 30 & Unknown \\
\hline $\mathrm{C}$ & Infertile/infertile & Delayed & 11 & $10(91)$ & $30 \quad(24-40)$ & $70-90$ \\
\hline D & Infertile/infertile & (Female/female) & 10 & $7(70)$ & $29 \quad(28-36)$ & 0 \\
\hline
\end{tabular}

Values significantly different from that of Group $\mathrm{C},{ }^{*} P<0.005, \dagger P<0.05$ (Fisher Exact Probability test). 
beginning of incubation. Fewer pairs in Group B than in Group C laid their next clutch within 45 days. This difference is probably not due to the initial exposure of the females in Group B to fertile eggs, because pairs exposed only briefly to fertile eggs (Group A) also laid their next clutch within 45 days significantly less often than pairs laying infertile eggs (Group C). There was no difference between Groups A and B in the number of laying pairs, despite the differences in the length of initial exposure to fertile eggs. Additional evidence that the timing of the subsequent oviposition is related to the fertility of the initial clutch is provided by the results for Group D: the proportion of these female/female pairs laying a subsequent clutch did not differ from that of male/female pairs producing infertile eggs (Group C).

\section{Latency to lay}

Of the doves that did lay a subsequent clutch within 45 days, there was no difference in the latency to the next clutch (Group A versus Group C, $\mathrm{U}=12, P>0.05$; Group C versus Group $\mathrm{D}, \mathrm{U}=35, P>0.05$ ). Since only one pair in Group B responded, valid comparisons of latency to lay could not be made between this group and the others.

\section{Discussion}

The differing proportion of fertile and infertile pairs laying a subsequent clutch within 45 days could not be attributed to differences either in their duration of incubation or in their styles of daily incubation. Regardless of the fertility of the eggs, some pairs stopped incubating a few days before laying a subsequent clutch, while others incubated continuously through the next oviposition. The correlation between the duration of incubation and the timing of the next oviposition is not statistically significant for fertile $\left(r_{s}=-0.70, P>0.05\right)$ or infertile $\left(r_{s}=0.19, P>0.05\right)$ pairs. In addition, female/female pairs (Group D), which do differ from male/female pairs in the duration of their incubation and in their daily incubation behaviour (T. O. Allen \& C. J. Erickson, unpublished observations), still laid their subsequent clutch as often within the 45 days as male/female pairs producing infertile eggs (Group C). Nor could the difference between fertile and infertile pairs be due to failure to copulate in Group C: copulation was observed by chance in three females, all of which laid subsequent clutches within 45 days. Cheng (1977) also has ruled out copulation per se as a factor. The accelerated egg laying in Group $\mathrm{C}$ females after a spontaneously infertile cycle could not have been due to individual peculiarities because these females did not habitually lay infertile eggs; all of them had laid fertile eggs just before this study and at least 7 of the 10 laid fertile eggs at the subsequent oviposition. (The fertility of 2 of the remaining clutches was unknown.) The timing of the subsequent oviposition is therefore related to the fertility or infertility of the initial clutch.

The results of this study extend the finding that doves laying infertile eggs recycle sooner than those laying fertile eggs (Cheng \& Follett, 1976; Cheng, 1977) by comparing pairs which had spontaneously produced infertile eggs to fertile pairs which had no squabs emerge. Cheng (1977) used females preselected for large ovarian follicles and induced them to lay infertile eggs by pairing them with castrated males.

The hormonal mechanism for the postponement of the subsequent egg laying in fertile pairs may involve a post-ovulatory decline in LH levels which occurs in females laying fertile, but not in females laying infertile, eggs (Cheng \& Follett, 1976). It is known that prolactin peaks near oviposition (March \& McKeown, 1973), that prolactin suppresses gonadotrophin release (Bates, Riddle \& Lahr, 1937), and that exogenous prolactin delays recycling in females induced to lay infertile eggs (Cheng, 1977); however, the association between prolactin and fertile eggs has yet to be established. 
Some interesting questions for future research arise from this study. Will these differences between fertile and infertile pairs in the timing of the next egg laying persist when no incubation is allowed? Does elevated prolactin near the time of oviposition serve a priming or permissive role in later, squab-induced prolactin release (Hansen, 1966; Buntin, 1977; Buntin, Cheng \& Hansen, 1977)? Also, the squab-induced crop sac growth of females which had laid fertile eggs should be compared to that of females which had laid infertile eggs.

In hamsters, mating releases prolactin (Avery \& Stahl, 1969); and the vagino-cervical stimulation at mating is a necessary prerequisite for normal parturition, which occurs more than 2 weeks later (Diamond, 1972). Similarly, the present study shows a rather unexpected relationship between events early and late in the reproductive cycle-events which seem also to be mediated by prolactin.

This work was supported by United States Health Service grants 1 T32 MH14259-01 and RO I HD04482. I thank Dr C. J. Erickson for his support and comments, and Dr N. T. Adler and Dr D. P. Crews for their comments on the manuscript.

\section{References}

Avery, T.L. \& Stahl, P. (1969) Quantitative changes in pituitary acidophils in cycling and mated Syrian hamsters. Biol. Reprod. 1, 152-156.

Bates, R.W., Riddle, O. \& Lahr, E.L. (1937) The mechanism of the antigonad action of prolactin in adult pigeons. Am.J. Physiol. 119, 610-614.

Buntin, J.D. (1977) Stimulus requirements for squabinduced crop sac growth and nest occupation in ring doves (Streptopelia risoria). J. comp. Physiol. Psychol. 91, 17--28.

Buntin, J.D., Cheng, M-F. \& Hansen, E.W. (1977) Effect of parental feeding activity on squab-induced crop sac growth in ring doves (Streptopelia risoria). Horm. \& Behav. 8, 197-209.

Cheng, M-F. (1977) Egg fertility and prolactin as determinants of reproductive recycling in doves. Horm. \& Behav. 9, 85-98.

Cheng, M-F. \& Follett, B.K. (1976) Plasma luteinizing hormone during the breeding cycle of the female ring dove. Horm. \& Behav. 7, 199-206.
Cuthbert, N.L. (1945) The ovarian cycle of the ring dove (Streptopelia risoria). J. Morph. 77, 351-377.

Diamond, M. (1972) Vaginal stimulation and progesterone in relation to pregnancy. Biol. Reprod. 6 , 281-287.

Hansen, E.W. (1966) Squab-induced crop growth in ring dove foster parents. J. comp. Physiol. Psychol. 62, 120-122.

March, G.L. \& MeKeown, B.A. (1973) Serum and pituitary prolactin changes in the Band-tailed pigeon (Columba tasciata) in relation to the reproductive cycle. Can.J. Physiol. Pharmac. 51, 583-589.

Siegal, S. (1956) Nonparametric Statistics for the Behavioral Sciences. McGraw-Hill, New York.

Whitman, C.o. (1919) The Behavior of Pigeons. Posthumous Works of C. O. Whitman, Vol. 3, pp. 28-35. Ed. H. A. Carr. Carnegie Institute, Washington, D.C.

Received 14 April 1978 